\title{
Treatment-Seeking Alcohol and Cocaine Dependent Individuals with High BMIs and below Average Fitness Levels
}

\author{
Jennifer G. Plebani \\ Department of Psychiatry, Perelman School of Medicine, University of Pennsylvania, Philadelphia, USA \\ Email: jplebani@mail.med.upenn.edu
}

Received 5 June 2015; accepted 20 June 2015; published 29 June 2015

Copyright (C) 2015 by author and OALib.

This work is licensed under the Creative Commons Attribution International License (CC BY). http://creativecommons.org/licenses/by/4.0/

(c) (i) Open Access

\begin{abstract}
Participation in sports and exercise has been shown to help prevent the development of substance use and abuse among adolescents. The protective mechanisms may involve mood, self-efficacy or simply the incompatibility between peak athletic performance and acute intoxication. In addition, prior research has found that aerobic exercise is useful for reducing tension and stress during recovery from substance use disorders (Read \& Brown, 2003). However, fitness and exercise levels among substance-dependent individuals have not yet been examined. As such, we chose to characterize baseline exercise and fitness levels for individuals entering outpatient substance abuse treatment as a prelude to examining activity, weight and other health changes during outpatient treatment. The NASA/Johnson Space Center Physical Activity Rating (PA-R) scale was developed to provide an estimate of a participant's fitness level using a self-reported regular physical activity, along with height, weight, age and gender (George et al., 1997). The PA-R was administered to 109 consecutively screened treatment-seeking individuals with cocaine, alcohol, or combined cocaine and alcohol (CAD) dependence. Additional data on height and weight, gender and race were gathered. Overall, fitness levels were below average for all subjects, and mean BMI was 29.24, with $43(39.45 \%)$ subjects classified as obese, $44(40.37 \%)$ as overweight and only $22(20.18 \%)$ as normal weight. PA-R findings indicate that fitness levels for participants were average or below. Taken together, findings indicate that there is substantial room for improving fitness and exercise among treatment-seeking substance-dependent subjects.
\end{abstract}

\section{Keywords}

BMI, Fitness, Cocaine, Alcohol

Subject Areas: Psychiatry \& Psychology

How to cite this paper: Plebani, J.G. (2015) Treatment-Seeking Alcohol and Cocaine Dependent Individuals with High BMIs and below Average Fitness Levels. Open Access Library Journal, 2: e1588. http://dx.doi.org/10.4236/oalib.1101588 


\section{Introduction}

Although prior research indicates that aerobic exercise is useful for reducing tension and stress during recovery from substance use disorders [1], it is unknown what role baseline fitness may play in substance dependence or recovery. It has been shown that those who drink alcohol regularly exercise more than non-drinkers, and that drinking and exercise are positively correlated [2]. Data on the protective effects of exercise in substance abuse prevention efforts suggest that higher fitness rates may lead to decreased substance use. If that is true, then exercise may be useful as a treatment, with fitness-related behaviors replacing drug-seeking behaviors [3].

As an initial investigation of baseline fitness levels among individuals entering substance abuse treatment, we sought to characterize baseline fitness levels among treatment seekers. In the future, this baseline data can be compared with treatment outcomes to see if baseline fitness impacts recovery.

\section{Methods}

To examine baseline fitness levels among substance-dependent individuals, the NASA/JSC Physical Activity Rating Scale (PA-R) [4] was administered to 109 consecutively screened treatment-seeking individuals with cocaine, alcohol, or combined cocaine and alcohol (CAD) dependence. Additional data on height, weight, age, gender and race were gathered. All participants signed consent to be screened for ongoing treatment research studies, and the measures included herein were part of that screening process, which was approved by the University of Pennsylvania Institutional Review Board.

The NASA/Johnson Space Center Physical Activity Rating (PA-R) scale was developed to provide an assessment score of $0-7$ on a person's level of regular physical activity [4]. There are a series of eight statements about routine physical activity. Participants are to select only one response that best describes their physical activity level. Possible responses include "I avoid walking or exertion", "I participate regularly in recreation or work requiring modest physical activity over one hour per week", and "I run over 10 miles per week or spend over 3 hours per week in comparable physical activity" [4] (CITE).

The PA-R values for this single response, along with the participants' age, gender, height and weight were used to calculate predicted $\mathrm{VO}_{2}$ max for participants. $\mathrm{VO}_{2}$ max is a measure of aerobic capacity, which is the maximum capacity of an individual's body to transport and utilize oxygen during incremental exercise, which reflects the physical fitness of the individual.

The formula for predicting $\mathrm{VO}_{2}$ max using the PA-R is:

Predicted $\mathrm{VO}_{2}$ Max $=\{[(0.133 \times$ age $)-(0.005($ age $\times$ age $)]+(11.403 \times$ gender $)+(1.463 \times$ PA-R $)+(9.17 \times$ height in meters $)-(0.254 \times$ weight in $\mathrm{kg})+34.142)\}$.

\section{Results}

Analyses were conducted using SPSS v. 22.0 (Armonk, NY: IBM Corp).

\subsection{Demographics}

Data were collected from 109 participants. The mean age of participants was 44.79 (SD = 9.92). Just over half of participants (57\%) were African American, while the remainder (43\%) were Caucasian. The majority of participants (70\%) were alcohol dependent, while $24 \%$ were dependent on both cocaine and alcohol, and the remaining $6 \%$ on cocaine alone.

\subsection{BMIs}

The majority of participants were either overweight or obese, with only $20 \%$ within normal BMI range. The percentage of participants above normal weight was comparable across racial groups, although a larger percentage of African Americans were overweight (44.1\%) versus obese (35.6\%), while the reverse was true for Caucasians, with more participants obese (44.7\%) than overweight (36.2\%). Women were more likely to be normal weight than men ( $29.4 \%$ vs. $17.5 \%)$, but were also more likely to be obese ( $47.1 \%$ vs. $38.5 \%)$ (Table 1 and Table 2).

\section{3. $\mathrm{VO}_{2} \mathrm{Max}$}

Overall, these subjects show overall poor fitness levels. Most are overweight or obese according to BMI data. In 
Table 1. Mean BMI by race and gender.

\begin{tabular}{ccc}
\hline & BMIs by race & \\
\hline & African American $(\mathrm{n}=62)$ & Caucasian $(\mathrm{n}=47)$ \\
\hline Normal weight & 20.3 & 19.1 \\
Overweight & 44.1 & 36.2 \\
Obese & 35.6 & 44.7 \\
\hline & BMIs by gender & Female $(\mathrm{n}=17)$ \\
\hline Normal weight & Male $(\mathrm{n}=92)$ & 29.4 \\
\hline Overweight & 17.5 & 23.5 \\
\hline Obese & 44 & 47.1 \\
\hline
\end{tabular}

Table 2. Mean $\mathrm{VO}_{2}$ max values and corresponding fitness levels by age and gender.

\begin{tabular}{ccccc}
\hline Age & \multicolumn{2}{c}{ Women } & \multicolumn{2}{c}{ Men } \\
\cline { 2 - 5 } $20-24$ & $\mathrm{VO}_{2}$ max & Fitness level & $\mathrm{VO}_{2}$ max & Fitness level \\
$25-29$ & 37.43 & Average & 45.27 & Average \\
$30-34$ & 31.88 & Fair & 41.04 & Fair \\
$35-39$ & ---- & ---- & 38.63 & Fair \\
$40-44$ & 29.79 & Fair & 42.51 & Average \\
$45-49$ & ---- & ---- & 37.23 & Average \\
$50-54$ & 30.03 & Average & 37.07 & Average \\
$55-59$ & 31.02 & Good & 35.30 & Average \\
$60-65$ & ---- & ---- & 33.69 & Fair \\
Overall & 25.61 & Good & 25.50 & ---- \\
\hline
\end{tabular}

addition, most report little exercise on the PA-R. $\mathrm{VO}_{2}$ max calculations show that subjects are of average fitness or below. Only older women showed above average fitness levels. All age groups of men showed average or fair fitness levels, as did all age groups of women except for those aged 50 - 54 and 60 - 65.

\section{Discussion}

These findings indicate that there is substantial room for improving fitness and exercise among treatment-seeking substance-dependent subjects. Improving fitness as part of treatment may help to address weight issues across substance classes. It has been well-documented that alcohol and weight have a complicated relationship, with most studies finding a J-shaped curve documenting that moderate alcohol consumption correlates to lower body weights than does either abstinence or heavier drinking [5]. It is known is that cocaine impacts fat metabolism such that active users have lower body fat than non-users even though they have poorer diets, and both groups have similar lean body mass [6] [7]. Therefore, current abstinence promoting treatments may lead to weight gain in bot cocaine and alcohol dependent participants. As such, exercise may be a viable adjunctive or stand-alone treatment for substance abuse to prevent weight gain and its associated health risks.

\section{Conclusion}

Future studies could incorporate exercise to determine what impact it has on treatment outcome [8]. In addition, exercise might improve the overall health of substance dependent subjects, improving quality of life in general. 


\section{References}

[1] Read, J.P. and Brown, R.A. (2003) The Role of Physical Exercise in Alcoholism Treatment and Recovery. Professional Psychology: Research and Practice, 34, 49-56. http://dx.doi.org/10.1037/0735-7028.34.1.49

[2] French, M.T., Popovici, I. and Maclean, J.C. (2009) Do Alcohol Consumers Exercise More? Findings from a National Survey. American Journal of Health Promotion, 24, 2-10. http://dx.doi.org/10.4278/ajhp.0801104

[3] Greer, T.L., Ring, K.M., Warden, D., Grannemann, B.D., Church, T.S., et al. (2012) Rationale for Using Exercise in the Treatment of Stimulant Use Disorders. Journal of Global Drug Policy and Practice, 6. http://ctndisseminationlibrary.org/display/825.htm

[4] George, J.D., Stone, W.J. and Burkett, L.N. (1997) Nonexercise $\mathrm{VO}_{2}$ Max Estimation for Physically Active College Students. Medicine and Science in Sports and Exercise, 29, 415-423. http://dx.doi.org/10.1097/00005768-199703000-00019

[5] Lukasiewicz, E., Mennen, L.I., Bertais, S., Arnault, N., Preziosi, P., Galan, P. and Hercberg, S. (2004) Alcohol Intake in Relation to Body Mass Index and Waist-to-Hip Ratio: The Importance of Type of Alcoholic Beverage. Public Health Nutrition, 8, 315-320.

[6] Ersche, K.D., Stochl, J., Woodward, J.M. and Fletcher, P.C. (2013) The Skinny on Cocaine: Insights into Eating Behavior and Body Weight in Cocaine-Dependent Men. Appetite, 71, 75-80. http://dx.doi.org/10.1016/j.appet.2013.07.011

[7] Billing, L. and Ersche, K.D. (2015) Cocaine's Appetite for Fat and the Consequences on Body Weight. American Journal of Drug and Alcohol Abuse, 41, 115-118. http://dx.doi.org/10.3109/00952990.2014.966196

[8] Trivedi, M.H., Greer, T.L., Church, T.S., Somoza, E., Blair, S.N., et al. (2011) Stimulant Reduction Intervention Using Dosed Exercise (STRIDE)—CTN 0037: Study Protocol for a Randomized Controlled Trial. Trials, 12, 206.

http://trialsjournal.com/content/12/1/206

http://dx.doi.org/10.1186/1745-6215-12-206 